Check for updates

Cite this: J. Mater. Chem. C, 2020 8,3730

Received 17th September 2019 Accepted 12th December 2019

DOI: $10.1039 / c 9 t c 05127 a$

rsc.li/materials-c

\title{
Application of ultrasonic sprayed zirconium oxide dielectric in zinc tin oxide-based thin film transistor
}

\author{
Abayomi T. Oluwabi, (D)*a Atanas Katerski, (D) a Emanuel Carlos, (D) \\ Rita Branquinho, (D) ${ }^{b}$ Arvo Mere, ${ }^{a}$ Malle Krunks, (D) ${ }^{a}$ Elvira Fortunato, (D) ${ }^{b}$ \\ Luis Pereira (D) ${ }^{b}$ and Ilona Oja Acik (D)*a
}

\begin{abstract}
Solution processing of metal oxides has been the focal point of interest for many researchers mainly because of the cost effectiveness and improved properties of metal oxides. However, achieving uniform and high-quality film deposition has been a recurring challenge using various wet-chemical techniques. Herein, we report a fully solution-based fabrication process exploiting both the ultrasonic spray pyrolysis (USP) and spin coating techniques owing to their simplicity, high degree of freedom for mixing metal oxide precursor salt, and larger area deposition. An amorphous zirconium oxide $\left(\mathrm{ZrO}_{x}\right)$ dielectric and zinc tin oxide (ZTO) semiconductor were deposited, respectively. The dielectric characteristics of the $\mathrm{ZrO}_{x}$ thin films were accessed by fabricating MIS-devices for the samples deposited at $200{ }^{\circ} \mathrm{C}$ and $400{ }^{\circ} \mathrm{C}$, which exhibited a capacitance of 0.35 and $0.67 \mu \mathrm{F} \mathrm{cm}{ }^{-2}$ at $100 \mathrm{kHz}$ and relative permittivity of 8.5 and 22.7, respectively. The $\mathrm{ZrO}_{x}$ thin film was then integrated as the gate dielectric layer in ZTO solution-processed thin film transistors, exhibiting a high electrical performance with low hysteresis $(-0.18 \mathrm{~V})$, high on/off current ratio of $10^{6}$ orders of magnitude, saturation mobility of $4.6 \mathrm{~cm}^{2} \mathrm{~V} \mathrm{~s}^{-1}$, subthreshold slope of $0.25 \mathrm{~V} \mathrm{dec}^{-1}$, and operating at a low voltage window of $3 \mathrm{~V}$. Based on these results, the as-fabricated $\mathrm{ZTO} / \mathrm{ZrO}_{x} \mathrm{TFT}$ opens the potential application of solution-processed transistors for low-cost electronic devices.
\end{abstract}

\section{Introduction}

Metal oxide materials are an excellent class of materials with enormous electronic functionalities depending on their area of usefulness, either as an insulator or a semiconductor. Recently metal oxide thin films have attracted significant interest for future electronic applications especially in thin film transistors (TFTs) due to their large-area uniformity, high mobility, good optical transparency in the visible light region, thermal stability, and excellent environmental impact, and they can be produced at low cost. ${ }^{1-5}$ However, most of these metal oxide transistors are incorporated into traditional silicon dioxide $\left(\mathrm{SiO}_{2}\right)$ dielectrics and they are operated at a high voltage window above $30 \mathrm{~V}$, which hinder their use in low-voltage,

\footnotetext{
${ }^{a}$ Laboratory of Thin Film Chemical Technologies, Department of Materials and Environmental Technology, Tallinn University of Technology, Ehitajate tee 5, 19086 Tallinn, Estonia.E-mail: abayomioluwabi@gmail.com, ilona.oja@ttu.ee ${ }^{b}$ CENIMAT/i3N Nova School of Science Technilogy (FCT-NOVA), Universidade NOVA de Lisboa and CEMOP/Uninova, Campus de Caparica, 2829-516 Caparica, Portugal

$\dagger$ Electronic supplementary information (ESI) available. See DOI: 10.1039/ c9tc05127a
}

smart and portable applications. Since the induced electric field directly corresponds to charge accumulation, replacing the $\mathrm{SiO}_{2}$ gate dielectric layer of TFTs with a high permittivity (high- $\kappa$ ) material would help accomplish low operation voltage. Furthermore, the scaling-down of electronic devices (below $100 \mathrm{~nm}$ ) has also called for the need to replace the $\mathrm{SiO}_{2}$ gate dielectric layer because of the problem of leakage current caused by the quantum tunnelling effect. ${ }^{2,6}$ Also, at a lower thickness (10-100 nm), a high- $\kappa$ gate dielectric can achieve high capacitance, allowing enough charge injection into the active layer of the transistor. ${ }^{2,7}$ Several inorganic high- $\kappa$ oxides such as titanium dioxide $\left(\mathrm{TiO}_{2}\right)$, zirconium dioxide $\left(\mathrm{ZrO}_{2}\right),{ }^{8,9}$ yttrium oxide $\left(\mathrm{Y}_{2} \mathrm{O}_{3}\right)$, tantalum oxide $\left(\mathrm{Ta}_{2} \mathrm{O}_{5}\right){ }^{10,11}$ hafnium oxide $\left(\mathrm{HfO}_{2}\right)^{12,13}$ and aluminium oxide $\left(\mathrm{Al}_{2} \mathrm{O}_{3}\right)^{14}$ have been investigated as attractive candidates to replace the $\mathrm{SiO}_{2}$ gate dielectric in TFTs. Barquinha et $a{ }^{11}{ }^{11}$ studied the behaviour and stability of transparent TFTs produced at low temperature using a multicomponent amorphous dielectric material. Their findings revealed that the $\mathrm{Ta}_{2} \mathrm{O}_{5}$ dielectric can help to improve the device performance based on the fact that this material has the tendency to increase amorphization when mixed with other dielectric materials with lower permittivity. 
Among the inorganic high- $\kappa$ dielectrics, zirconium oxide $\left(\mathrm{ZrO}_{x}\right)$ is a desirable gate insulator because bulk $\mathrm{ZrO}_{2}$ has a high permittivity value $(\sim 25)$, low leakage current, good thermal stability, adequate band alignment and forms good adhesion with Si-substrates. ${ }^{3,15}$ Most importantly, the wide bandgap (5.0-7.8 eV) of $\mathrm{ZrO}_{x}$ is beneficial to suppress charge penetration from the gate electrode and to reduce the generation of charge as a result of the thermal/ photoexcitation process. ${ }^{8}$ In the past, good quality $\mathrm{ZrO}_{x}$ thin films have been deposited using different methods, for example, atomic layer deposition, sputtering, chemical vapour deposition, and e-beam evaporation, ${ }^{16}$ but these methods are very expensive and the growth rate of the thin film is time consuming due to the high vacuum. As opposed to the vacuum-based methods, solution-based method such as spin coating, dip coating, inkjet printing, and spray pyrolysis (SP) offer additional advantages including cost effectiveness, simplicity, high degree of freedom, and larger area of deposition. .,9,11-19 $^{-19}$

Interestingly, among the many wet-chemical methods, ultrasonic spray pyrolysis (USP) is an excellent thin film deposition technique, offering an easy deposition process that gives room for free mixing of precursor solutions at the molecular level before deposition. The cost-effectiveness and non-selective tendency to any substrate of USP distinguish it among several other solution processes. It can easily be scaled up for industrial or commercial fabrication processes and still maintain good film uniformity over a wide area. ${ }^{18,20}$ Ortiz et al. ${ }^{21}$ fabricated a cubic phase of $\mathrm{ZrO}_{x}$ thin film by SP, and Oluwabi et al. ${ }^{17,20}$ reported the deposition of $\mathrm{ZrO}_{x}$ thin film by USP. Wang et al. ${ }^{22}$ reported that a $\mathrm{ZrO}_{x}$ dielectric deposited by SP has a low leakage current $\left(1.2 \times 10^{-7} \mathrm{~A} \mathrm{~cm}^{-2}\right)$ and a high dielectric breakdown of $9.5 \mathrm{MV} \mathrm{cm}^{-1}$ at a substrate temperature below $350{ }^{\circ} \mathrm{C}$.

Moreover, to achieve reliable TFTs, the optimum band offset between the conduction band of the dielectric in an n-type transistor device must be above $1 \mathrm{eV}$ with respect to that of the channel layer in order to reduce the leakage caused by the Schottky effect, ${ }^{2,23}$ and $\mathrm{ZrO}_{x}$ can help prevent such effect. Owing to its physical and chemical properties, $\mathrm{ZrO}_{x}$ has been employed in various TFTs, such as MoS, organic, graphene and oxide TFTs. ${ }^{24-26}$ As part of the TFT, the channel layer is significant especially in transparent amorphous semiconductors, as suggested by Honoso et $a .^{27}$ Although solution-processed metal oxide semiconductors, namely, indium zinc oxide (IZO) and indium gallium zinc oxide (IGZO), have been reported as attractive choices of the channel layer, indium-free semiconductors such as zinc tin oxide (ZTO), among others have also attracted significant attention due to the scarcity of naturally available indium resources, ${ }^{27,29}$ enabling competitive device performance in comparison with their indium-based counterparts. ${ }^{28,30}$ The ZTO semiconductor has good applicability in TFT, but typically requires a high deposition temperature (above $350{ }^{\circ} \mathrm{C}$ ), and the mechanism of its synthesis has not been fully comprehended. Salgueiro et $a .^{31}$ reported the role organic solvents in the performance of solution-processed zinc tin oxide (ZTO)-based TFTs. Table 1 presents the reported solution-processed $\mathrm{ZrO}_{x}$ dielectric TFTs. Adamopoulos et $a .^{32}$ reported a fully solutionprocessed TFT by SP with a $\mathrm{ZrO}_{x}$ gate dielectric operating at a low voltage with high mobility. Similarly, Xinge et al. ${ }^{22}$ fabricated a fully solution-processed TFT by spray combustion synthesis (SCS) to achieve a device with high carrier mobility and good reliability. Also, several solution-processed $\mathrm{ZrO}_{x}$ dielectric TFTs have been reported via spin coating. ${ }^{3,25,26,33}$

In this work, we demonstrate a combination of ultrasonic spray pyrolysis (USP) and spin coating in the fabrication of highquality $\mathrm{ZrO}_{x}$ gate dielectrics and ZTO semiconductor, respectively, onto a rigid substrate. To the best of our knowledge, this is the first report of an all-amorphous oxide TFT with low operational voltage. Furthermore, the introduction of USP into our device fabrication process allowed the fabrication of the TFT over a larger area, it improved the properties of the gate dielectric layer and eliminated the problem of pinholes, which have the tendency to jeopardise the final performance of the TFT device. In our previous publication, $\mathrm{ZrO}_{x}$ thin films were tested only as a capacitor, but herein, we further tested a $\mathrm{ZrO}_{x}$ thin film with a thickness of $\sim 30 \mathrm{~nm}$ as both a capacitor and gate dielectric in TFTs, which is considerably lower than the thickness of $\mathrm{ZrO}_{x}$ in our previous report. ${ }^{17,18,20}$

\section{Experimental details}

\subsection{Precursor solution preparation}

The $\mathrm{ZrO}_{x}$ precursor solution was prepared by dissolving zirconium(Iv) acetyl acetonate $\left(\mathrm{Zr}\left(\mathrm{C}_{5} \mathrm{H}_{7} \mathrm{O}_{2}\right)_{4}\right.$; Sigma-Aldrich, 98\%) in methanol (Me-OH, $\mathrm{CH}_{3} \mathrm{OH}$; Sigma-Aldrich, 99\%) at room

Table 1 Reports on the various solution-processed $\mathrm{ZrO}_{x}$ gate dielectrics at different temperatures in the range of $250{ }^{\circ} \mathrm{C} \leq T \leq 500{ }^{\circ} \mathrm{C}$ tested in TFT devices

\begin{tabular}{|c|c|c|c|c|c|c|c|c|c|c|c|}
\hline \multicolumn{4}{|c|}{ Gate dielectric layer } & \multicolumn{4}{|l|}{ Channel layer } & \multicolumn{3}{|c|}{ Transistor parameters } & \multirow[b]{2}{*}{ Ref. } \\
\hline Method & Material & $T\left({ }^{\circ} \mathrm{C}\right)$ & Structure & Method & Material & $T\left({ }^{\circ} \mathrm{C}\right)$ & Structure & $\begin{array}{l}\text { Mobility } \\
\left(\mathrm{cm}^{2} \mathrm{~V}^{-1} \mathrm{~S}^{-1}\right)\end{array}$ & $V_{\text {on }}(\mathrm{V})$ & $\begin{array}{l}\text { SS } \\
\left(\mathrm{V} \mathrm{dec}^{-1}\right)\end{array}$ & \\
\hline Spin coating & $\mathrm{ZrO}_{x}$ & 400 & Crystalline & Spin coating & $\mathrm{InO}_{x}$ & 300 & Crystalline & 4.42 & 0.31 & 0.07 & 3 \\
\hline Spin coating & $\mathrm{ZrO}_{x}$ & 300 & Amorphous & Spin coating & $\mathrm{NiO}_{x}$ & 250 & Amorphous & 4.8 & -1.6 & 0.35 & 8 \\
\hline Spin coating & $\mathrm{ZrO}_{x}$ & 250 & Amorphous & Spin coating & $\operatorname{InO}_{x}$ & 250 & Amorphous & 10.0 & 0 & 0.1 & 8 \\
\hline Spin coating & $\mathrm{ZrO}_{x}$ & 500 & Crystalline & Spin coating & ZTO & 500 & Crystalline & 2.50 & 1 & 0.23 & 34 \\
\hline Spin coating & $\mathrm{ZrO}_{x}$ & 350 & Amorphous & Spin coating & IZO & 250 & Amorphous & 0.16 & 0 & 1.49 & 26 \\
\hline Spin coating & $\mathrm{ZrO}_{x}$ & 400 & Crystalline & Spin coating & $\mathrm{SnO}_{x}$ & 350 & Crystalline & 2.50 & -0.5 & 0.30 & 33 \\
\hline SCS & $\mathrm{ZrO}_{x}$ & 350 & Amorphous & SCS & IGZO & 350 & Amorphous & 28.5 & 0.3 & - & 22 \\
\hline Spray pyrolysis & $\mathrm{ZrO}_{x}$ & 400 & Crystalline & Spray pyrolysis & $\mathrm{ZnO}$ & 400 & Crystalline & 32.0 & -1 & - & 32 \\
\hline Spray pyrolysis & $\mathrm{ZrO}_{x}$ & 400 & Amorphous & Spin coating & ZTO & 350 & Amorphous & 4.60 & -0.9 & 0.25 & Present study \\
\hline
\end{tabular}


temperature to yield a solution with a $\mathrm{Zr}^{4+}$ ion concentration of $0.025 \mathrm{M}$, and the solution was constantly stirred for at least $30 \mathrm{~min}$ to ensure complete dissolution of the solute in the solvent. The solution was completely transparent and remained transparent even after aging.

The zinc oxide precursor solution was prepared by dissolving zinc nitrate salt (zinc nitrate hexahydrate; Sigma-Aldrich, 98\%) in 2-methoxyl ethanol (ME) (Roth, 98\%). The tin oxide precursor was prepared from a tin chloride source (tin(II) chloride; SigmaAldrich, 98\%) dissolved in ME solvent. Both the zinc and tin oxides solutions were prepared at a metal ion concentration of $0.1 \mathrm{M}$ and stirred for about $12 \mathrm{~h}$. The ZTO precursor was made by mixing the corresponding zinc and tin oxide precursor solutions in the ratio of $2: 1$. The resulting solution was then stirred for $1 \mathrm{~h}$ to ensure homogeneity and finally filtered through a hydrophilic filter with a $0.20 \mu \mathrm{m}$ pore size before use.

The ZTO precursor solution was characterized by thermogravimetry and differential scanning calorimetry (TG-DSC) analysis of the $0.1 \mathrm{M}$ solution of the ZTO precursor to account for methoxy propanol solvent evaporation events. TG-DSC analyses were performed under an air atmosphere up to $550{ }^{\circ} \mathrm{C}$ with a $10{ }^{\circ} \mathrm{C} \mathrm{min}{ }^{-1}$ heating rate in an aluminium crucible using a simultaneous thermal analyser (TG-DSC - STA 449 F3 Jupiter, Netzsch).

\subsection{Thin film deposition and characterisation}

Prior to the film deposition, all substrates (p-type silicon wafer and quartz with $2 \times 2 \mathrm{~cm}^{2}$ ) were rinsed in an ultrasonic bath at $60{ }^{\circ} \mathrm{C}$ in acetone, isopropanol, and distilled water for $15 \mathrm{~min}$ respectively, and were later dried in air. $\mathrm{ZrO}_{x}$ dielectric films were deposited via the ultrasonic spray pyrolysis (USP) technique as shown in Fig. 1a, and the deposition parameters have been reported in. ${ }^{17}$ For the purpose of this study, the films were deposited at both $200{ }^{\circ} \mathrm{C}$ and $400{ }^{\circ} \mathrm{C}$ without further annealing.

The film structure was assessed by glancing angle X-ray diffraction (GAXRD) performed on an X'Pert PRO PANalytical powder diffractometer using $\mathrm{Cu} \mathrm{K} \alpha$ line radiation $(\lambda=1.540598 \AA)$ with the angle of incidence of the X-ray beam fixed at $0.9^{\circ}$.
The thickness of ZTO and $\mathrm{ZrO}_{x}$ was obtained by spectroscopic ellipsometry measurement in the energy range of 1.5-6.0 eV with an incident angle of $70^{\circ}$ using a Jobin Yvon Uvisel system. Total transmittance spectra were obtained using a Jasco-V670 spectrophotometer equipped with an integrating sphere in the wavelength range of $200-800 \mathrm{~nm}$, which was later used to calculate the optical bandgap of the $\mathrm{ZrO}_{x}$ dielectric at different deposition temperatures. Surface morphology was studied using a ZEISS HR Ultra 55 scanning electron microscope (SEM). The acceleration voltage for SEM measurements was $4.0 \mathrm{kV}$. Attenuated total reflectance (ATR) Fourier transform infrared spectroscopic characterization of the thin films deposited on silicon substrates was performed in the range of $4500-560 \mathrm{~cm}^{-1}$.

\subsection{Fabrication of $\mathrm{ZrO}_{x}$ MIS devices}

The dielectric characteristics of $\mathrm{ZrO}_{x}$ were accessed through metal-insulator-semiconductor (MIS) capacitors by depositing the $\mathrm{ZrO}_{x}$ thin film onto p-type silicon substrates $(1-3 \Omega \mathrm{cm})$, as described above. Al gate electrodes ( $80 \mathrm{~nm}$ thick) with an area of $8.0 \times 10^{-3} \mathrm{~cm}^{2}$ were deposited by thermal evaporation via a shadow mask, and a similar thickness of Al film was also deposited on the back of the silicon wafer to improve the ohmic conductivity. Electrical characterization was performed by measuring both the current-voltage $(I-V)$ and capacitancevoltage $(C-V)$ characteristics of the devices using a semiconductor device analyser (Keysight 1500A) connected to a Casecade M150 microprobe station inside a dark box at room temperature with humidity between $30 \%$ and $40 \%$. The capacitance-frequency $(C-F)$ curve was obtained from the impedance data measured in the range of $10 \mathrm{~Hz}$ to $1 \mathrm{MHz}$ using an AUTOLAB PGSTAT30/2.

\subsection{Fabrication of $\mathrm{ZrO}_{x}$ TFT devices}

TFTs were produced in a staggered bottom-gate, top-contact architecture by depositing the $\mathrm{ZrO}_{x}$ thin films onto p-type silicon substrates, as described above and shown in Fig. 1a and $b$. The ZTO active layer was later deposited by spin coating (using a Laurell Technologies instrument). Four layers of $0.1 \mathrm{M}$

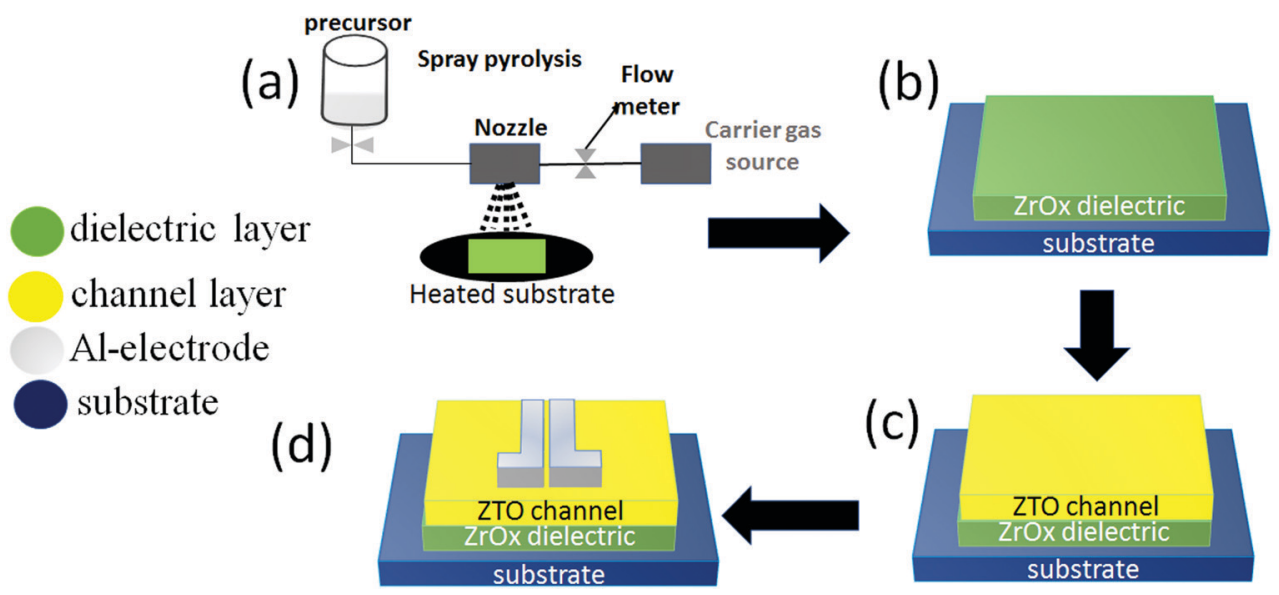

Fig. 1 Fabrication stages of $\mathrm{ZrO}_{x}$ gate dielectric TFT devices with ZTO semiconductor layer: (a) spraying of $\mathrm{ZrO}_{x}$ precursor solution, (b) deposition of $\mathrm{ZrO}_{x}$ dielectric onto Si-substrate, (c) spin coating ZTO semiconductor onto $\mathrm{ZrO} / \mathrm{Si}$, and (d) aluminium electrode deposition, yielding a TFT device with the channel width $(W)$ of $1400 \mu \mathrm{m}$ and length of $100 \mu \mathrm{m}(W / L=14)$. 
ZTO precursor solution was spun for $35 \mathrm{~s}$ at $2000 \mathrm{rpm}$ onto the $\mathrm{ZrO}_{x}$ thin films and annealed at $150{ }^{\circ} \mathrm{C}, 250{ }^{\circ} \mathrm{C}$, and $350{ }^{\circ} \mathrm{C}$ for $30 \mathrm{~min}$ (Fig. 1c). Finally, the source and drain aluminum electrodes (100 $\mathrm{nm}$ thick) were deposited by thermal evaporation via a shadow mask onto the annealed films (Fig. 1d). The output and the transfer characteristics of the devices were obtained in continuous mode with both back and forth sweeps recorded in ambient conditions inside a Faraday cage (in dark conditions) using a semiconductor parameter analyzer (Agilent 4155C).

The saturation mobility $\left(\mu_{\text {sat }}\right)$ was determined from the following equation: ${ }^{14}$

$$
I_{\mathrm{d}}=\left(\frac{C_{\mathrm{ZrO}} B \mu_{\mathrm{sat}}}{2 L}\right)\left(V_{\mathrm{G}}-V_{\mathrm{T}}\right)^{2}
$$

where $C_{\mathrm{Zro}}$ is the gate dielectric capacitance per unit area, $B$ and $L$ are the channel width and length, respectively, $V_{\mathrm{G}}$ is the gate voltage, and $V_{T}$ is the threshold voltage, which was determined in the saturation regime by fitting of the curve of $I_{\mathrm{d}}^{1 / 2}$ versus $V_{\mathrm{G}}$ and extrapolating the linear part to $V_{\mathrm{G}}$ axis.

\section{Results and discussion}

\section{1 $\mathrm{ZrO}_{x}$ dielectric thin film characterisation}

The surface morphology of the $\mathrm{ZrO}_{x}$ dielectric films deposited at different temperatures was observed via atomic force microscope (AFM, Fig. 2a and c) and SEM analysis (Fig. 2b and d). The films surface roughness was estimated from the AFM height profile and scanned through an area of $1 \mu \mathrm{m} \times 1 \mu \mathrm{m}$. The $\mathrm{ZrO}_{x}$ films deposited at $200{ }^{\circ} \mathrm{C}$ (Fig. 2a) demonstrated a higher surface roughness with a root mean square (RMS) roughness value of $0.33 \mathrm{~nm}$ compared with that deposited at $400{ }^{\circ} \mathrm{C}$ with an RMS value of $0.29 \mathrm{~nm}$. The decrease in the film surface roughness at higher temperature could be due to film densification, which was aided by the decomposition of volatile organic precursor during the spray pyrolysis process. According to the TG/DTG/DTA results of Oja et al. ${ }^{35,36}$ for spray-deposited $\mathrm{TiO}_{2}$ dielectrics, the complete decomposition of volatile organic complexes occurs above $400{ }^{\circ} \mathrm{C}$. In addition, the deposited $\mathrm{ZrO}_{x}$ films were structurally amorphous
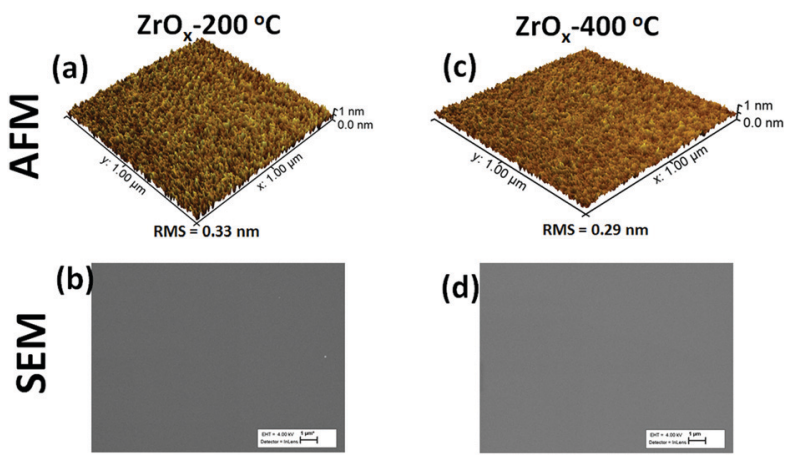

(d)

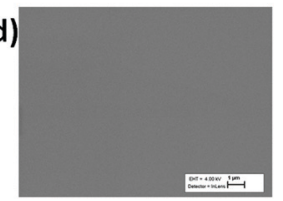

Fig. 2 Surface morphology of the solution-processed $\mathrm{ZrO}_{x}$ dielectric films. AFM deflection images of the as-deposited $\mathrm{ZrO}_{x}$ dielectric at both (a) $200{ }^{\circ} \mathrm{C}$, and (c) $400{ }^{\circ} \mathrm{C}$; and their corresponding SEM images at (b) $200{ }^{\circ} \mathrm{C}$ and (d) $400{ }^{\circ} \mathrm{C}$ on an Si-substrate.

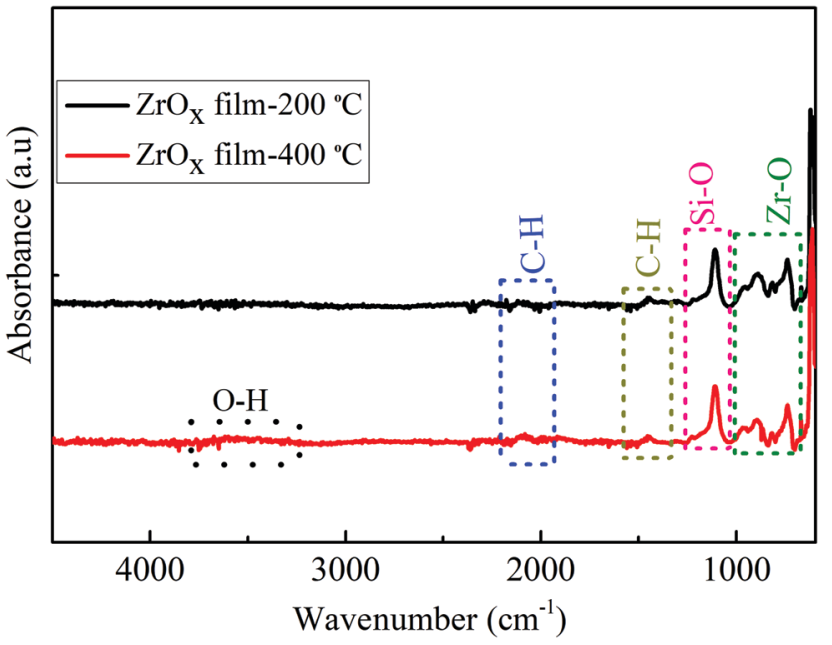

Fig. 3 FTIR ATR absorbance spectra of $\mathrm{ZrO}_{x}$ dielectric films deposited at $200{ }^{\circ} \mathrm{C}$ and $400{ }^{\circ} \mathrm{C}$.

(see Fig. S1 in the ESI $\dagger$ ) as confirmed by X-ray diffraction. Furthermore, as depicted by the SEM images (Fig. $2 \mathrm{~b}$ and $\mathrm{d}$ ), the $\mathrm{ZrO}_{x}$ dielectric films were uniform, compact, and very smooth.

The FT-IR spectra of the deposited $\mathrm{ZrO}_{x}$ dielectric thin films deposited at $200{ }^{\circ} \mathrm{C}$ and $400{ }^{\circ} \mathrm{C}$ on Si-substrates is shown in Fig. 3. All the films show a sharp infrared absorbance peak at $1120 \mathrm{~cm}^{-1}$, which can be ascribed to the optical stretching of the $\mathrm{Si}-\mathrm{O}$ bond from the Si-substrate. The asymmetric $\mathrm{CH}_{3}$ deformation vibration centred at $1430 \mathrm{~cm}^{-1}$ was observed and a slightly broad peak at $3545 \mathrm{~cm}^{-1}$ associated with the bending and stretching vibrational bond of the native $\mathrm{O}-\mathrm{H}$ group from the adsorbed water molecules on the surface of the $\mathrm{ZrO}_{x}$ dielectric was also observed. ${ }^{13}$

Furthermore, a weak absorbance peak centred at $2110 \mathrm{~cm}^{-1}$ corresponding to the $\mathrm{C}-\mathrm{H}$ bond stretching was observed for both films, which can be ascribed to the organic residues from the $\mathrm{ZrO}_{x}$ precursor reagent; thereby suggesting the presence of organic residue in the $\mathrm{ZrO}_{x}$ dielectric film network even after annealing at $400{ }^{\circ} \mathrm{C}$. Both the $\mathrm{ZrO}_{x}$ dielectric films deposited at $200{ }^{\circ} \mathrm{C}$ and $400{ }^{\circ} \mathrm{C}$ exhibited infrared absorption peaks centred at 880,750 , and $945 \mathrm{~cm}^{-1}$, which are related to the metal oxygen bond $(\mathrm{Zr}-\mathrm{O})$ stretching. ${ }^{13,31}$

The optical transmittance of the as-deposited $\mathrm{ZrO}_{x}$ dielectric film at $200{ }^{\circ} \mathrm{C}$ and $400{ }^{\circ} \mathrm{C}$ is shown in Fig. 4a. The absence of interference fringes on the transmittance spectra indicates that the films are very thin, which was later confirmed by spectroscopic ellipsometry $\left(\sim 20 \mathrm{~nm}\right.$ and $\sim 30 \mathrm{~nm}$ thick for the $200{ }^{\circ} \mathrm{C}$ and $400{ }^{\circ} \mathrm{C}$ deposited films, respectively). It was observed that both deposited $\mathrm{ZrO}_{x}$ dielectric films demonstrated a high optical transparency in the visible region $(350-700 \mathrm{~nm})$ with a percentage transmittance of above $80 \%$.

In addition, the transmittance decreased with an increase in the deposition temperature, which can be attributed to the changes in the film microstructure, although it was impossible to be detected by XRD since the films are amorphous according to the $\mathrm{XRD}$ result $(\mathrm{ESI} \dagger \mathrm{S} 1, \mathrm{XRD})$. Another reason may be because of the removal of oxygen vacancies in the film when they were 

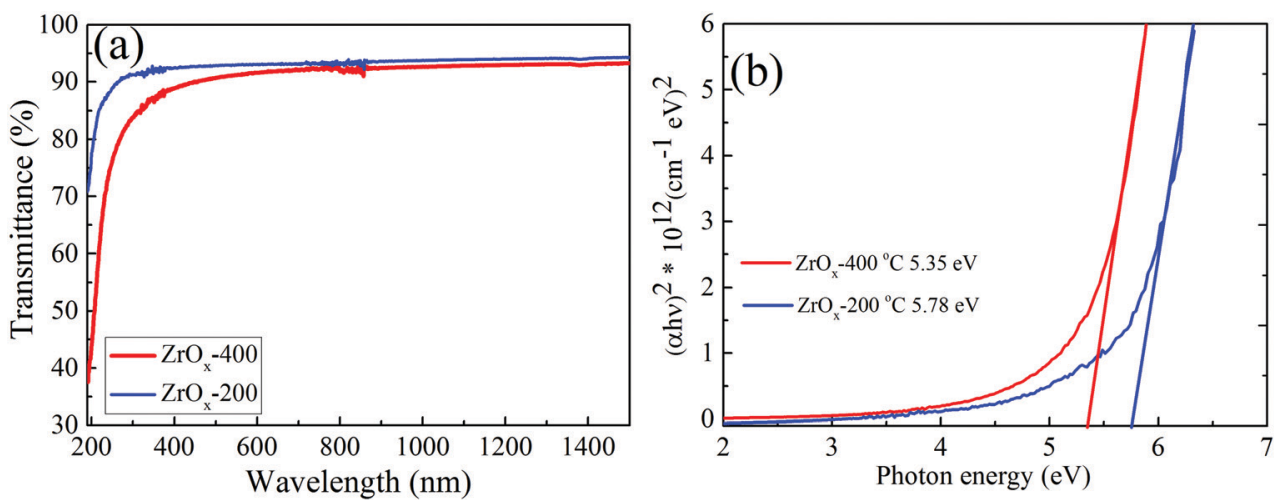

Fig. 4 (a) Total transmittance spectra of the $\mathrm{ZrO}_{x}$ dielectric film deposited at $200{ }^{\circ} \mathrm{C}$ and $400{ }^{\circ} \mathrm{C}$ and (b) corresponding bandgap extrapolation in the Tauc plots.

grown at $400{ }^{\circ} \mathrm{C}$. A similar tendency was reported in our previous publication. ${ }^{8,17}$ The optical bandgap $\left(E_{\mathrm{g}}\right)$ was estimated by fitting the transmittance spectra to the standard Tauc plot, ${ }^{37}$ which was determined to be 5.78 and $5.35 \mathrm{eV}$ for the $\mathrm{ZrO}_{x}$ films deposited at $200{ }^{\circ} \mathrm{C}$ and $400{ }^{\circ} \mathrm{C}$, respectively (Fig. $4 \mathrm{~b}$ ). The reduction in the $E_{\mathrm{g}}$ value with the deposition temperature can be attributed to many reasons, including microstructural changes within the film, the presence of localised defects within the $\mathrm{ZrO}_{x}$ band structure thereby causing a reduction in the $E_{\mathrm{g}}$ value, and the disordered nature of the amorphous materials. ${ }^{3,8,17}$ Nevertheless, the $E_{\mathrm{g}}$ values being generally high above $5 \mathrm{eV}$ is a good indication that the spray-deposited $\mathrm{ZrO}_{x}$ dielectric film would provide enough barrier needed to prevent carrier conduction between the active layer and the gate dielectric layer of TFT.

\section{2. $\mathrm{ZrO}_{x}$ MIS characterisation}

To demonstrate the insulating property of the sprayed $\mathrm{ZrO}_{x}$ dielectric thin film, an MIS-capacitor with the $\mathrm{Al} / \mathrm{p}-\mathrm{Si} / \mathrm{ZrO}_{x} / \mathrm{Al}$ structure was fabricated. The capacitance-frequency $(C-F)$ dispersion curves in Fig. 5 a show that the area capacitance at $100 \mathrm{kHz}$ for the $\mathrm{ZrO}_{x}$ dielectric film deposited $200{ }^{\circ} \mathrm{C}$ and $400{ }^{\circ} \mathrm{C}$ is $0.37,0.67 \mu \mathrm{F} \mathrm{cm}{ }^{-2}$, corresponding to a permittivity of 8.4
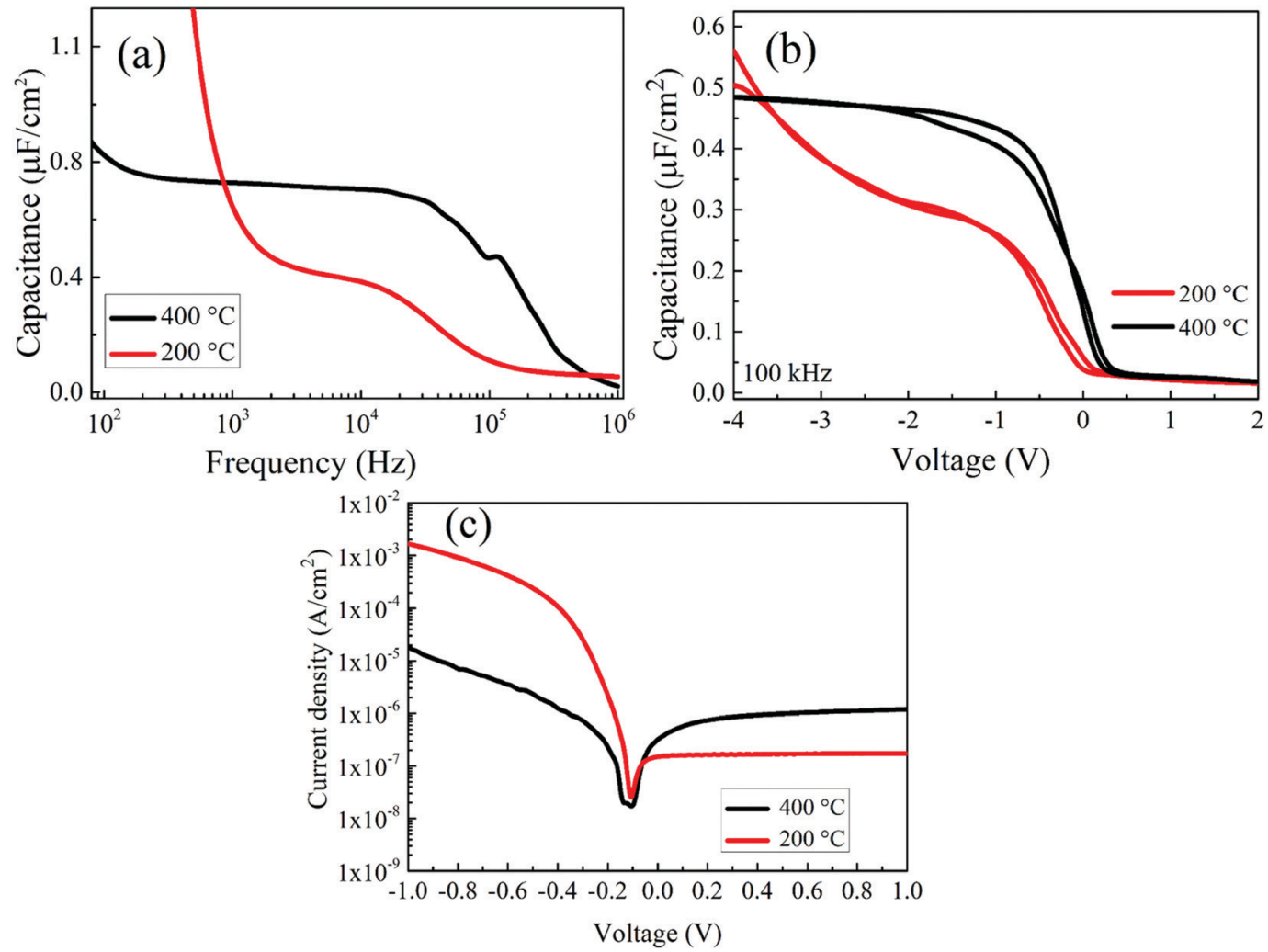

Fig. 5 (a) Capacitance-frequency curve, (b) capacitance-voltage, and (c) current-voltage characteristics of Al/p-type Si/ZrO $/ \mathrm{Al}$ MIS capacitors with the $\mathrm{ZrO}_{x}$ films obtained at various deposition temperatures. 
and 22.7, respectively. The observed increase in the permittivity value of the $400{ }^{\circ} \mathrm{C}$ deposited film can be due to the densification of the film at a higher temperature. An important point is that the observed increase in the dispersion curve for $\mathrm{ZrO}_{x}$ deposited at $200{ }^{\circ} \mathrm{C}$ as the frequency decreases may be an indication that there is another dielectric relaxation mechanism at lower frequencies related with mobile ionic species as a result of the incomplete decomposition of the $\mathrm{ZrO}_{x}$ precursors at a low temperature.

Fig. 5b shows the capacitance-voltage curves for both the $200{ }^{\circ} \mathrm{C}$ and $400{ }^{\circ} \mathrm{C}$ deposited $\mathrm{ZrO}_{x}$ dielectric films. The voltage bias was carried in the forward and reverse sweep at $100 \mathrm{kHz}$, to ascertain the stability of the MIS capacitor. When the $\mathrm{ZrO}_{x}$ film was deposited at $400{ }^{\circ} \mathrm{C}$, there was a saturation of the capacitance in the accumulation regime, which did not occur for that at $200{ }^{\circ} \mathrm{C}$ due to the leakage current (as confirmed in Fig. 5c). Moreover, and contrary to that for the film deposited at $200{ }^{\circ} \mathrm{C}$, there are no bumps when reaching accumulation, indicating a reduction in the density of electron trap sites at the interface between $\mathrm{ZrO}_{x}$-silicon. Depending on the type of shift in the $C-V$ curve, an understanding about the charge trapping/de-trapping within the oxide band structure can be obtianed. ${ }^{14}$ In our case, the device produced at $200{ }^{\circ} \mathrm{C}$ showed that a more negative bias was needed to complete accumulation due to electron trapping, corroborating the $C-F$ results.

Fig. 5c shows the plot of the current density against voltage for the $200{ }^{\circ} \mathrm{C}$, and $400{ }^{\circ} \mathrm{C}$ deposited $\mathrm{ZrO}_{x}$ dielectrics. From the plot, the leakage behaviour of the $\mathrm{ZrO}_{x}$ gate dielectric films was estimated from in the reverse bias regime at $1 \mathrm{~V}$. It was observed that the $\mathrm{ZrO}_{x}$ deposited at $400{ }^{\circ} \mathrm{C}$ has a lower leakage current of $3.56 \times 10^{-6} \mathrm{~A} \mathrm{~cm}^{-2}$ that is lower than the one measured for the $200{ }^{\circ} \mathrm{C}$ deposited dielectric film $\left(4.26 \times 10^{-4} \mathrm{~A} \mathrm{~cm}^{-2}\right)$. The observed decrease in the leakage current is 2 orders of magnitude and can be attributed to the decomposition of volatile organic compounds in the film at higher temperature, resulting in the improvement of the density of the dielectric films. ${ }^{8,17}$

\subsection{ZTO semiconductor thin film formation and characterisation}

The semiconductor, ZTO, film was formed via a simple sol-gel synthesis approach, and the ZTO precursor is a mixture of both
Zn-nitrate and Sn-chloride salts and dispersed in ME at a mole ratio of $2: 1$ at room temperature. The thermal gravimetry and differential calorimetry analyses for both the $\mathrm{Zn}$-nitrate and the Sn-chloride precursor solution were studied and are presented in Fig. S2(a) and (b), ESI, $\uparrow$ respectively. The degradation of the $\mathrm{Zn}$-nitrate precursor is very fast with almost $80 \%$ degradation below $200{ }^{\circ} \mathrm{C}$, while the degradation of the Sn-precursor is fairly slow requiring a minimum temperature of $400{ }^{\circ} \mathrm{C}$ to complete the decomposition process. On the other hand, the gravimetric and differential scanning calorimetry analyses for the ZTO precursor solution is presented in Fig. S3(a and b), respectively, and the total residual mass loss for the decomposition process from $20-550{ }^{\circ} \mathrm{C}$ is $70.28 \%$. Thus, to obtain the desired ZTO thin film phase, the reaction is expected to occur at a much higher temperature (preferably, above $400{ }^{\circ} \mathrm{C}$ ).

The FTIR spectrum of the ZTO precursor solution made from the ME solution is presented in [S5] and the FTIR spectra of the ZTO semiconductor thin films produced from this solution at various annealing temperatures are presented in Fig. 6a. All the ZTO semiconductor films show a sharp infrared absorbance peak at $1120 \mathrm{~cm}^{-1}$, which can be related to the optical stretching of the $\mathrm{Si}-\mathrm{O}$ bond from the Si-substrate, and they equally exhibited infrared absorption peaks centred at 880, 750, and $945 \mathrm{~cm}^{-1}$, corresponding to the metal oxide bond ( $\mathrm{Zn}-\mathrm{O}$ and $\mathrm{Sn}-\mathrm{O})$ stretching. ${ }^{13,31}$ This result indicates that the ZTO films were composed of some metal oxygen bonds and organic residues. The microstructures of the ZTO thin films at various annealing temperatures were measured using XRD, and the results are shown in Fig. 6b. The absence of obvious peaks in the X-ray diffraction patterns demonstrate the amorphous nature of the ZTO thin films.

\subsection{Electrical properties of solution-processed TFTs based on $\mathrm{SiO}_{2}$ gate dielectric}

Based on the above discussion on the properties of the $\mathrm{ZrO}_{x}$ thin film, it can be inferred that the films deposited at a higher temperature displayed better dielectric characteristics. Nevertheless, to juxtapose this behaviour in TFTs, we first investigated the feasibility of a solution-processed ZTO active layer in a bottom gate and top source/drain contact architecture.
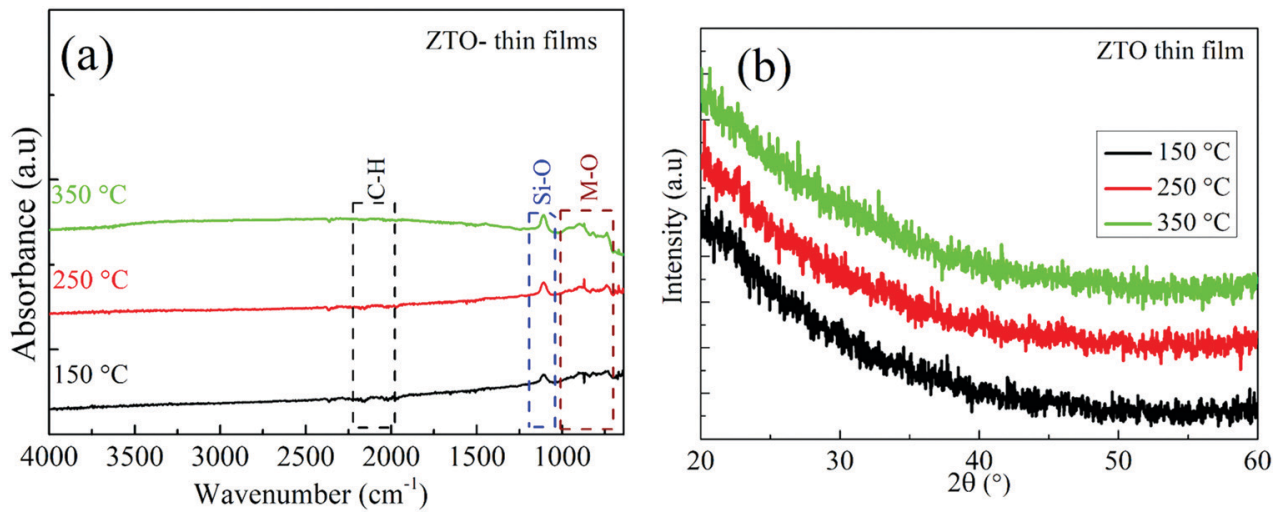

Fig. 6 (a) FTIR spectra of the ZTO semiconductor thin films annealed at various temperatures. (b) XRD patterns of the ZTO semiconductor thin films annealed at various temperatures. 

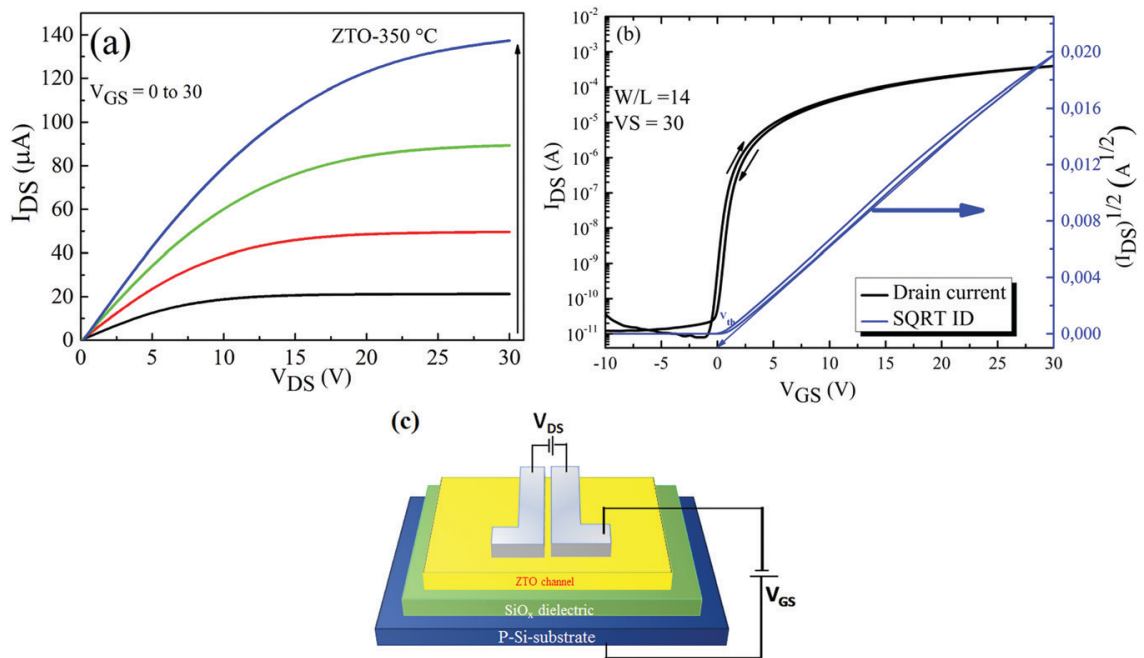

Fig. 7 TFT characteristics of the $\mathrm{ZTO}-350 / \mathrm{SiO}_{2}$ device. (a) Output, and (b) transfer performance; while a schematic representation of the device structure is shown in (c).

The conventional $\mathrm{SiO}_{2} / \mathrm{Si}$-substrate was used as the gate electrode and gate dielectric because of its reliability and low defect density. Fig. 7 shows the output and the transfer characteristics of the solution-processed ZTO-TFT and scheme of the TFT architecture. The output curve of the ZTO-TFT after annealing at $350{ }^{\circ} \mathrm{C}$ shows that the device has a clear distinction between the linear and the saturation regimes (Fig. 7a). The absence of overcrowding data points at the low drain voltage region demonstrates the excellent ohmic contact between the Al electrode and the ZTO channel layer. The TFT trans-conduction characteristics are depicted in Fig. 7b, which showed very little hysteresis during the sweep of the gate voltage in both the forward and reverse directions. The result of the saturation mobility was extracted by fitting the transconductance curve to eqn (1), and the statistical summary of both the TFT and MIS devices is presented in Table $\mathrm{S} 1$ (ESI $\dagger)$. The calculated saturation mobility $\left(\mu_{\text {sat }}\right)$ is $\sim 0.5 \mathrm{~cm}^{2} \mathrm{~V}^{-1} \mathrm{~s}^{-1}$, the threshold voltage $\left(V_{\mathrm{th}}\right)$ is $1.3 \mathrm{~V}$, the on-off current ratio $\left(I_{\text {on }} / I_{\text {off }}\right)$ is up to $10^{8}$, the sub-threshold swing (S.S.) is $760 \mathrm{mV}$ per decade, the hysteresis is $-0.4 \mathrm{~V}$, and the onvoltage $\left(V_{\text {on }}\right)$ is $-0.5 \mathrm{~V}$. The extracted device parameters are also summarised in Table 2. The SS value was used to estimate the density of the interface state $\left(D_{\text {it }}\right)$ of $1.1 \times 10^{12} \mathrm{~cm}^{2}$ for the ZTO-TFT device using eqn (2):

$$
D_{\mathrm{it}}=\left[\frac{\mathrm{SS} \log (e)}{k T / q}-1\right] \frac{C_{\mathrm{i}}}{q}
$$

where $k, T$, and $q$ are Boltzmann's constant, absolute temperature, and electronic charge, respectively. However, the Dit value is significantly lower as opposed to what has been reported for ZTO-TFTs fabricated using other techniques. ${ }^{38}$ It can also the attributed to the ZTO thin film deposition technique yielding good quality film (Fig. S4 in the ESI $\dagger$ ) at a high annealing temperature, which aided the good adhesion between the $\mathrm{ZTO} / \mathrm{SiO}_{2}$ interface. ${ }^{39}$

On the contrary, the behaviour of ZTO-TFT produced after annealing at $250{ }^{\circ} \mathrm{C}$ (see Fig. S6 in the ESI $\dagger$ ) is of poor quality and the device exhibited a huge hysteresis voltage and high $V_{\text {th }}$ of about $8 \mathrm{~V}$, meaning that more power will be required to turn-on the device. This can be due to the low quality of the channel layer at a lower temperature because the ZTO semiconductor layer at $250{ }^{\circ} \mathrm{C}$ has more organic residue compared to that at $350{ }^{\circ} \mathrm{C}$. This assumption is consistent with the observation from the TG analysis of the $\mathrm{Zn}$ (II) precursor compared with the $\mathrm{Sn}$ (II) precursor (see Fig. S1a and b in the ESI $\dagger$ ). According to the study by Sanctis et al. ${ }^{28}$ the degree of oxidation of the ZTO semiconducting layer plays a crucial role in the performance of ZTO-based TFTs because of the of oxygen defects arising from the highly defective $\mathrm{SnO}_{2}$ within the ZTO semiconductor layer.

\subsection{Electrical properties of solution-processed TFT based on $\mathrm{ZrO}_{x}$ gate dielectric}

The electrical performance of the TFTs presented in the previous section proved that solution-processed ZTO can be adopted as the active layer in TFTs. Here, we demonstrate the applicability of the $\mathrm{ZrO}_{x}$ dielectric as a likely replacement for the $\mathrm{SiO}_{2}$ dielectric layer in improving the performance of ZTO-based TFTs. To avoid the problem of charge trapping at the interface between the dielectric and channel layers, only the $\mathrm{ZrO}_{x}$ thin film processed at $400{ }^{\circ} \mathrm{C}$ was tested, and to reduce the inaccuracy when

Table 2 Summary of the TFT parameters for both the $\mathrm{ZTO} / \mathrm{SiO}_{2}$ and $\mathrm{ZTO} / \mathrm{ZrO}_{x}$ devices

\begin{tabular}{|c|c|c|c|c|c|c|c|}
\hline Device & $V_{\text {on }}(\mathrm{V})$ & $I_{\mathrm{on}} / I_{\mathrm{off}}$ & Sat. mob. $\left(\mathrm{cm}^{2} \mathrm{~V}^{-1} \mathrm{~s}^{-1}\right)$ & $V_{\mathrm{Th}}(\mathrm{V})$ & $\mathrm{SS}\left(\mathrm{V} \mathrm{dec}{ }^{-1}\right)$ & Hysteresis (V) & $D_{\text {it }}\left(\mathrm{cm}^{-2}\right)$ \\
\hline ZTO-250/SiO $x$ & $7.80 \pm 0.2$ & $\sim 10^{4}$ & - & $\sim 8.45$ & - & $1.71 \pm 0.5$ & - \\
\hline ZTO-350/SiO & $-0.30 \pm 0.5$ & $\sim 10^{8}$ & $0.47 \pm 0.01$ & $1.32 \pm 0.08$ & $0.76 \pm 0.01$ & $-0.37 \pm 0.08$ & $1.1 \times 10^{12}$ \\
\hline ZTO-350/ZrO $x^{-400}$ & $-0.94 \pm 0.04$ & $\sim 10^{6}$ & $4.61 \pm 0.06$ & $0.03 \pm 0.02$ & $0.25 \pm 0.01$ & $-0.18 \pm 0.06$ & $5.7 \times 10^{12}$ \\
\hline
\end{tabular}



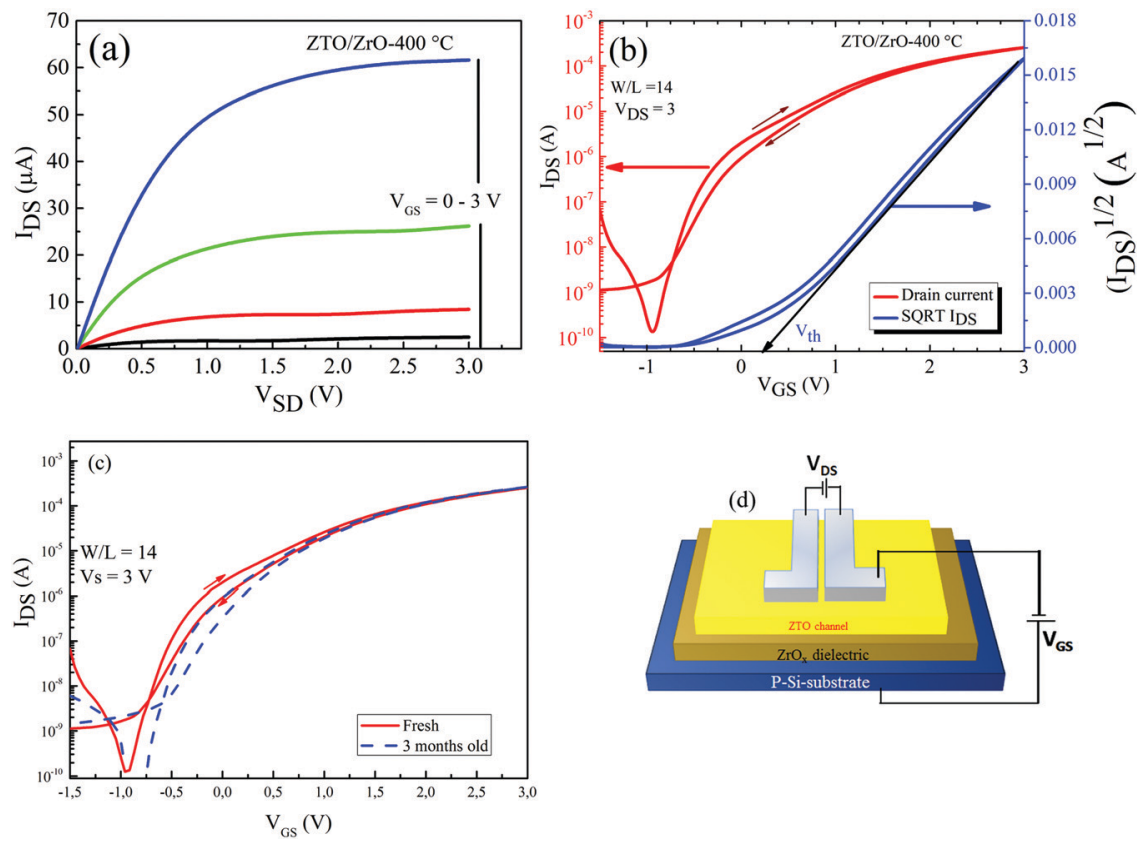

Fig. 8 TFT characteristics of ZTO-350/ZrO -400 devices. (a) Output, and (b) transfer performance; while (c) transfer characteristic of both the freshly made device and the performance after 3 months shelf-life, and the schematic representation of the device structure is shown in (d).

calculating the mobility and SS since the devices are characterised in a quasi-static regime, the capacitance $\left(C=1.0 \mu \mathrm{F} \mathrm{cm} \mathrm{cm}^{-2}\right)$ of $\mathrm{ZrO}_{x}$ was calculated at $50 \mathrm{~Hz}$. The typical transfer and output characteristics of the as-fabricated TFTs and the corresponding device schematic are shown Fig. 8a-d. It can be seen in Fig. 8a that again, the device exhibited a clear distinction between the linear and saturation regimes and no current crowding was observed. Fig. 8b shows the typical transfer characteristics of the $\mathrm{ZrO}_{x}$-TFT device, and it can be seen that the off-state $\left(I_{\text {off }}\right)$ current increased with a decrease in the gate voltage. This observation is typical of most high- $\kappa$ metal oxide derivatives, which has been reported to be caused by their relative narrow bandgap. ${ }^{10,11}$ Contrary to the ZTO/SiO ${ }_{2}$ TFTs, the ZTO/ZrO ${ }_{x}$ TFT demonstrated a significant reduction in its operation voltage window (between $-1 \mathrm{~V}$ and $3 \mathrm{~V}$ ), higher saturation mobility of $4.6 \mathrm{~cm}^{2} \mathrm{~V}^{-1} \mathrm{~s}^{-1}, I_{\mathrm{on}} / I_{\text {off }}$ ratio of $10^{6}$, small SS value of $250 \mathrm{mV}$ per decade, and a turn-on voltage of $-0.9 \mathrm{~V}$. The improvement in the transistor parameters is mainly due to the higher permittivity of the $\mathrm{ZrO}_{x}$ thin film compared with that of the $\mathrm{SiO}_{2}$ dielectric. The $\mathrm{ZrO}_{x}$-based TFT dissipated a much lower power $(0.3 \mathrm{~mW})$ than TFT based on the $\mathrm{SiO}_{2}$ dielectric $(30 \mathrm{~mW}) .^{8}$

In our case, the clockwise hysteresis was estimated to be $-0.1 \mathrm{~V}$, which means that electron trapping occurred during forward sweeping. During the reverse gate voltage sweeping, these states remain filled until the trapped electrons were thermally de-trapped. ${ }^{3}$ Moreover, $D_{\mathrm{it}}$ is very important for device stability and charge carrier mobility, which was estimated to be $5.7 \times 10^{12} \mathrm{~cm}^{-2}$ for the $\mathrm{ZTO} / \mathrm{ZrO}_{x}$ TFT. These results show that we obtained a good interface between the $\mathrm{ZrO}_{x}$ gate dielectric and the ZTO channel layer. Also, despite being larger than that using $\mathrm{SiO}_{2}$ as the dielectric, the $D_{\text {it }}$ value is comparable to the reported values for solution-processed $\mathrm{ZrO}_{x}$ TFTs $\left(1 \times 10^{12} \mathrm{~cm}^{-2}\right),{ }^{8,38}$ and much lower than that for sputtered TFT devices. ${ }^{40}$ The improved performance is believed to have originated from the thin and amorphous structure of the $\mathrm{ZrO}_{x}$ gate dielectric, providing a smooth interface between the $\mathrm{ZrO}_{x}$ dielectric and ZTO semiconductor layer.

The aging stability of the fabricated $\mathrm{ZTO} / \mathrm{ZrO}_{x}$ TFT device was accessed by re-measuring its performance after 3 months of storage without encapsulation or any specific storage conditions (Fig. 8c). The device showed excellent stability with time and no significant changes in its electrical performance was observed, indicating it demonstrates an effective performance towards cost-effective and low operation voltage solution-based oxide electronics. This may be as a result of the slow sensitivity of the active ZTO layer to native contaminants such as dust and moisture, which have a tendency of increasing the surface energy of semiconductor materials. Moreover, the degradation of the active layer of metal oxide-based TFTs is mostly due their sensitivity to surface adsorbates such as $\mathrm{H}_{2} \mathrm{O}$ molecules and humidity, which act as trap sites for mobile carriers, and therefore cause depletion of the active layer material. ${ }^{41}$ Another reason for the shelf-life stability of the device can be due to the in situ deposition of the ZTO layer at high temperature, which led to the formation of a ZTO film with less defects, surface adsorbed species, and organic contaminants. Riedl et al. ${ }^{41}$ demonstrated that in situ annealing can also be used to improve the stress stability of ALD-processed ZTO-based TFTs.

\section{Conclusions}

In summary, we successfully reported the solution processing of $\mathrm{ZrO}_{x}$ thin films via a low-cost ultrasonic spray pyrolysis method 
and explored their applicability as a gate dielectric layer in TFTs. The fabricated $\mathrm{ZrO}_{x}$ films were uniform, smooth, amorphous, and optically transparent with an $E_{\mathrm{g}}$ value of $5.35 \mathrm{eV}$. The $\mathrm{ZrO}_{x}$ film exhibited a relative permittivity value of $22.7(50 \mathrm{~Hz})$ and leakage current of $3.56 \times 10^{-6} \mathrm{~A} \mathrm{~cm}^{-2}$ at a bias of $1 \mathrm{~V}$. The optimized $\mathrm{ZTO} / \mathrm{SiO}_{2}$ TFTs annealed at $350{ }^{\circ} \mathrm{C}$ exhibited excellent electrical performances, including a saturation mobility of $0.5 \mathrm{~cm}^{2} \mathrm{~V}^{-1} \mathrm{~s}^{-1}$, a high $I_{\mathrm{on}} / I_{\text {off }}$ value of $10^{8}$, a threshold voltage of $1.32 \mathrm{~V}$, and a small sub-threshold swing value of $0.76 \mathrm{~V} \mathrm{dec}^{-1}$. The $\mathrm{SiO}_{2}$ gate dielectric was replaced by the sprayed-deposited $\mathrm{ZrO}_{x}$ dielectric to achieve a cost-effective and fully solutionprocessed device. The $\mathrm{ZTO} / \mathrm{ZrO}_{x}$ TFTs exhibited a low operation voltage of $3 \mathrm{~V}$ with optimized performances, including a high saturation mobility of $4.6 \mathrm{~cm}^{2} \mathrm{~V}^{-1} \mathrm{~s}^{-1}$, a low threshold voltage of $0.03 \mathrm{~V}$, appreciable $I_{\mathrm{on}} / I_{\text {off }}$ current ratio of $10^{6}$, and a small sub-threshold swing of $0.25 \mathrm{~V} \mathrm{dec}^{-1}$. These results demonstrate that the use of a very simple technique, such as both ultrasonic spray pyrolysis and spin coating for the sequential deposition of high- $\kappa$ gate dielectrics and metal oxide semiconductors represents a significant step towards the development of low-cost, large-area oxide TFTs.

\section{Conflicts of interest}

There are no conflicts to declare.

\section{Acknowledgements}

This study was financially supported by the Estonian Ministry of Education and Research project IUT194; and by Portuguese National Funds through FCT - Portuguese Foundation for Science and Technology, Reference UID/CTM/50025/2019 and FCT/MCTES; and by the European Union through the European Regional Development Fund project TK141 "Advanced materials and high-technology devices for energy recuperation systems"; and European Institute of Innovation and Technology (EIT RawMaterials, Horizon 2020) Supersmart, Scale-Up of Printed Electronics, Grant Agreement 17161. A. T. Oluwabi acknowledges Archimedes Foundation for financing the study mobility program, through the "DoRa Plus Action 1", E. Carlos acknowledges FCT/MCTES for a doctoral grant (Grant SFRH/BD/116047/2016). Authors acknowledge Dr V. Mikli of Taltech for SEM measurement, J. V. Pinto, Ana Pimentel, and T. Sequeira of CENIMAT for the XRD, TG/DSC, and AFM measurements respectively.

\section{References}

1 G. X. Liu, A. Liu, F. K. Shan, Y. Meng, B. C. Shin, E. Fortunato and R. Martins, High-performance fully amorphous bilayer metal-oxide thin film transistors using ultra-thin solution-processed $\mathrm{ZrO}_{x}$ dielectric, J. Appl. Phys. Lett., 2014, 105(11), 113509.

2 P. Barquinha, R. Martins, L. Pereira and E. Fortunato, Transparent oxide electronics, United Kingdom, John Wiley and Sons, 2012.
3 L. Zhu, G. He, J. Lv, E. Fortunato and R. Martins, Fully solution-induced high-performance indium oxide thin film transistors with $\mathrm{ZrO}_{x}$ high- $\kappa$ gate dielectrics, RSC Adv., 2018, 8, 16788.

4 Y. Duan, F. Sun, Y. Yang, P. Chen, D. Yang, Y. Duan and X. Wang, Thin-Film Barrier Performance of Zirconium Oxide Using the Low-Temperature Atomic Layer Deposition Method, ACS Appl. Mater. Interfaces, 2014, 6, 3799-3804.

5 A. Liu, G. X. Liu, H. H. Zhu, F. Xu, E. Fortunato, R. Martins and F. K. Shan, Eco-friendly, solution-processed In-W-O thin films and their applications in low-voltage, high-performance transistors, ACS Appl. Mater. Interfaces, 2014, 6, 17364.

6 M. Hirose, M. Koh, W. Mizubayashi, H. Murakami, K. Shibahara and S. Miyazaki, Fundamental limit of gate oxide thickness scaling in advanced MOSFETs, Semicond. Sci. Technol., 2000, 15, 485-490.

7 X. Donga, G. Xia, Q. Zhang, L. Li, H. Gong, J. Bi and S. Wang, Room-temperature UV-ozone assisted solution process for zirconium oxide films with high dielectric properties, Ceram. Int., 2017, 43, 15205-15213.

8 C. Zhu, A. Liu, G. Liu, G. Jiang, Y. Meng, E. Fortunato, R. Martins and F. Shan, Low-temperature, nontoxic waterinduced high- $\kappa$ zirconium oxide dielectrics for low-voltage, high-performance oxide thin-film transistors, J. Mater. Chem. C, 2016, 4, 10715.

9 G. Adamopoulos, S. Thomas, P. H. Wöbkenberg, D. D. C. Bradley, M. A. McLachlan and T. D. Anthopoulos, HighMobility Low-Voltage $\mathrm{ZnO}$ and Li-Doped ZnO Transistors Based on $\mathrm{ZrO}_{2}$ High-k Dielectric Grown by Spray Pyrolysis in Ambient Air, Adv. Mater., 2011, 23, 1894-1898.

10 S. Clima, G. Pourtois, A. Hardy, S. Van Elshocht, M. K. Van Bael, S. De Gendt, D. J. Wouters, M. Heyns and J. A. Kittl, Dielectric Response of $\mathrm{Ta}_{2} \mathrm{O}_{5}, \mathrm{Nb}_{2} \mathrm{O}_{5}$, and $\mathrm{NbTaO}_{5}$ from first principles investigations, J. Electrochem. Soc., 2010, 157, G20-G25.

11 P. Barquinha, L. Pereira, G. Goncalves, R. Martins, D. Kuscer, M. Kosec and E. Fortunato, Performance and Stability of Low Temperature Transparent Thin-Film Transistors Using Amoorphous Multicomponent Dielectrics, J. Electrochem. Soc., 2009, 156(11), H824-H831.

12 J. Tardy, M. Erouel, A. L. Deman, A. Gagnaire, V. Teodorescu, M. G. Blanchin, B. Canut, A. Barau and M. Zaharescu, Organic Thin Film Transistors With $\mathrm{HFO}_{2}$ high- $\kappa$ Gate Dielectric Grown By Anodic Oxidation Or Deposited By Sol-Gel, Microelectron. Reliab., 2007, vol. 47, 372-377.

13 E. Carlos, R. Branquinho, A. Kiazadeh, J. Martins, P. Barquinha, R. Martins and E. Fortunato, Boosting Electrical Performance of high- $\kappa$ Nanomultilayer Dielectrics and Electronic Devices by Combining Solution Combustion Synthesis and UV Irradiation, ACS Appl. Mater. Interfaces, 2017, 9, 40428-40437.

14 E. Carlos, R. Branquinho, A. Kiazadeh, P. Barquinha, R. Martins and E. Fortunato, UV-mediated photochemical treatment for low-temperature oxide based thin film transistor, ACS Appl. Mater. Interfaces, 2016, 8(45), 31100-31108.

15 D. Panda and T.-Y. Tseng, Growth, dielectric properties, and memory device applications applications of $\mathrm{ZrO}_{2}$ thin films, Thin Solid Films, 2013, 531, 1-20. 
16 K. Kukli, M. Ritala and M. Leskelä, Low-temperature deposition of zirconium oxide based nanocrystalline films by alternate supply of $\mathrm{Zr}\left[\mathrm{OC}\left(\mathrm{CH}_{3}\right)_{3}\right]_{4}$ and $\mathrm{H}_{2} \mathrm{O}$, Chem. Vap. Deposition, 2000, 6(6), 297-302.

17 A. T. Oluwabi, I. Oja Acik, A. Katerski, A. Mere and M. Krunks, Structural and electrical characterisation of high- $\kappa \mathrm{ZrO}_{2}$ thin films deposited by chemical spray pyrolysis method, Thin Solid Films, 2018, 662, 129-136.

18 A. Juma, I. Oja Acik, A. T. Oluwabi, A. Mere, V. Mikli, M. Danilson and M. Krunks, Zirconium doped $\mathrm{TiO}_{2}$ thin films deposited by chemical spray pyrolysis, Appl. Surf. Sci., 2016, 387, 539-545.

19 B. Wang, W. Huang, L. Chi, M. Al-Hashimi and T. J. Marks, high- $\kappa$ Gate Dielectrics for Emerging Flexible and Stretchable Electronics, Chem. Rev., 2018, 118(11), 5690-5754.

20 A. T. Oluwabi, A. Juma, I. Oja-Acik, A. Katerski, A. Mere and M. Krunks, Effect of $\mathrm{Zr}$ doping on the structural and electrical properties of spray deposited $\mathrm{TiO}_{2}$ thin films, Proc. Est. Acad. Sci., 2018, 67(2), 147-157.

21 A. Ortiz, J. C. Alonso and E. Haro-Poniatowsk, Spray deposition and characterization of zirconium-oxide, J. Electron. Mater., 2005, 34(2), 150-155.

22 B. Wang, X. Yu, P. Guo, W. Huang, L. Zeng, N. Zhou, L. Chi, M. J. Bedzyk, R. P. H. Chang, T. J. Marks and A. Facchetti, Solution-Processed All-Oxide Transparent High-Performance Transistors Fabricated by Spray-Combustion Synthesis, Adv. Electron. Mater., 2016, 2, 1500427.

$23 \mathrm{~J}$. Robertson and B. Falabretti, Band Offsets of High K Gate Oxides on High Mobility Semiconductors, Mater. Sci. Eng., $B, 2006,135,267-271$.

24 H. J. Kwon, J. Jang and C. P. Grigoropoulos, Laser direct writing process for making electrodes and high- $\kappa$ sol-gel $\mathrm{ZrO}_{2}$ for boosting performances of $\mathrm{MoS}_{2}$ transistors, ACS Appl. Mater. Interfaces, 2016, 8, 9314-9318.

25 W. He, W. Xu, Q. Peng, C. Liu, G. Zhou, S. Wu, M. Zeng, Z. Zhang, J. Gao and X. Gao, Surface modification on solution processable $\mathrm{ZrO}_{2}$ high- $\kappa$ dielectrics for low voltage operations of organic thin film transistors, J. Phys. Chem. C, 2016, 120, 9949-9957.

26 S. J. Kim, D. H. Yoon, Y. S. Rim and H. J. Kim, LowTemperature Solution-Processed $\mathrm{ZrO}_{2}$ Gate Insulators for Thin-Film Transistors Using High-Pressure Annealing, Electrochem. Solid-State Lett., 2011, 14(11), E35-E37.

27 K. Nomura, H. Ohta, A. Takagi, T. Kamiya, M. Hirano and H. Hosono, Room-temperature fabrication of transparent flexible thin-film transistors using amorphous oxide semiconductors, Nature, 2004, 432, 488-492.

28 S. Sanctis, N. Koslowski, R. Hoffmann, C. Guhl, E. Erdem, S. Weber and J. J. Schneider, Toward an Understanding of Thin-Film Transistor Performance in Solution-Processed
Amorphous Zinc Tin Oxide (ZTO) Thin Films, ACS Appl. Mater. Interfaces, 2017, 9, 21328-21337.

29 P. K. Nayak, J. V. Pinto, G. Gonçalves, R. Martins and E. Fortunato, Environmental, optical, and electrical stability study of solution-processed zinc-tin-oxide thin film transistors, J. Disp. Technol., 2011, 7, 640.

30 S. Jeong, Y. Jeong and J. Moon, Solution-processed zinc tin oxide semiconductor for thin-film transistors, J. Phys. Chem. C, 2008, 112, 11082-11085.

31 D. Salgueiro, A. Kiazadeh, R. Branquinho, L. Santos, P. Barquinha, R. Martins and E. Fortunato, Solution based zinc tin oxide TFTs: the dual role of the organic solvent, J. Phys. D: Appl. Phys., 2017, 50, 065106.

32 G. Adamopoulos, A. Bashir, P. H. Wöbkenberg, D. D. Bradley and T. D. Anthopoulos, High-Mobility Low-Voltage ZnO and Li-Doped ZnO Transistors Based on $\mathrm{ZrO}_{2}$ High-k Dielectric Grown by Spray Pyrolysis in Ambient Air, Appl. Phys. Lett., 2009, 95, 133507.

33 J. Jang, R. Kitsomboonloha, S. L. Swisher, E. S. Park, H. Kang and V. Subramanian, Transparent High-Performance Thin Film Transistors from Solution-Processed $\mathrm{SnO}_{2} / \mathrm{ZrO}_{2}$ Gel-like Precursors, Adv. Mater., 2013, 25, 1042-1047.

34 C.-G. Lee, S. Dutta and A. Dodabalapur, Solution-Processed ZTO TFTs With Recessed Gate and Low Operating Voltage, IEEE Electron Device Lett., 2010, 31(12), 1410-1412.

35 I. Oja Acik, J. Madarász, M. Krunks, K. Tonsuaadu, G. Pokol and L. Niinistö, Titanium(Iv) acetylacetonate xerogels for processing titania films: A thermoanalytical study, J. Therm. Anal. Calorim., 2009, 97(1), 39-45.

36 M. Krunks, I. Oja Acik, K. Tõnsuaadu, M. Es-Souni, M. Gruselle and L. Niinistö, Thermonalitical study of acetylacetonatemodified titinium(Iv) isopropoxide as a precursor for $\mathrm{TiO}_{2}$ films, J. Therm. Anal. Calorim., 2005, 80, 483-488.

37 J. I. Pankove, Optical Process in Semiconductors, PrenticeHall, Englewood Cliffs, N.J., 1971, p. 422.

38 T.-J. Ha and A. Dodabalapur, Photo stability of solutionprocessed low-voltage high mobility zinc-tin-oxide $/ \mathrm{ZrO}_{2}$ thin-film transistors for transparent display applications, Appl. Phys. Lett., 2013, 102, 123506.

39 K. Okamura, B. Nasr, R. A. Brand and H. Hahn, Solutionprocessed oxide semiconductor SnO in p-channel thin-film transistors, J. Mater. Chem., 2012, 22, 4607-4610.

40 J. Li, F. Zhou, H. P. Lin, W. Q. Zhu, J. H. Zhang, X. Y. Jiang and Z. L. Zhang, SiOx interlayer to enhance the performance of InGaZnO TFT with $\mathrm{AlO}_{x}$ gate insulator, Curr. Appl. Phys., 2012, 12, 1288-1291.

41 M. Fakhri, P. Görrn and T. Riedl, Stability and encapsulation of metal-oxide based TFTs, in Active-Matrix Flat panel Displays and Devices (AM-FPD), 2013. 